\title{
Methods of educational sciences in the first class
}

\author{
Tolipova Tursuntosh Karshievna ${ }^{1}$ \\ ${ }^{1}$ Retraining and qualification of the workers of the Samarkand regional public education \\ Teacher of the Regional Development Center, Uzbekistan
}

Email:t.tolipova@umail.uz

\begin{abstract}
This article details in detail the implementation of innovative approaches in the system of general secondary education and its pedagogical and psychological principles, which play an important role in the upbringing of individuals. The author has widely analyzed the objectives, principles and results of teaching natural science in the primary grades. It also describes the principles of pedagogical mastery and shows ways of inviting, enhancing and reinforcing students. In particular, the article emphasizes that an innovative approach to teaching natural science can enhance the effectiveness of education.
\end{abstract}

Keywords: natural science, science, education system, personality, pedagogy, psychology, pedagogical skills, individual approach.

\section{INTRODUCTION}

Teaching natural science is mainly based on pedagogical research, practical work, and personal observation. In teaching natural science, the teacher should not only provide theoretical knowledge, but also develop the knowledge, skills and abilities needed for practical activities. It also requires students to develop their mentality, will, character and mental abilities. Accordingly, he develops modern methods of teaching natural science. The learning process involves interdependent components: the content of the subject, the activities of teachers and students, the acquisition of knowledge, skills and abilities.

The methodology of teaching natural science is not only describing and explaining the learning process, it also develops rules so that a teacher can successfully teach children about the subject. The teaching methodology of natural science covers all teaching processes, from teacher training to defining learning outcomes, including classroom, home, classroom and out-of-school work. On the basis of a comprehensive study of the teaching practice and the creative summarizing of the results, certain teaching patterns are established. Specifically, specific measures will be developed to apply subject-based instruction based on the law of direct perception of studied objects (plants and animals).

The areas of study of the methodology of natural science include: the educational and educational importance of natural science as a subject of study, its role in the system of education; content of the educational material and system of its distribution; teaching methods and forms of student organization; accounting of learning materials, the process of learning and learning outcomes of students; equip and use teaching materials; extracurricular and non-classroom activities, material resources for teaching. The methodology of natural science teaching allows for the study of natural phenomena in interconnection and development.

Natural science methodology is also closely related to physiology, anatomy, hygiene, botany, zoology, geography, agrotechnics, meteorology, logic and psychology. The integration of these subjects is reflected in the ability of the teacher to master the basics of these subjects, to distinguish the most important of them, and to explain the material in a manner appropriate to the age of the students. After all, the role of natural science in the education of a harmonious personality is invaluable. Evidence of a particular type of activity - reading, work, learning, communication - is important.

Proper communication with nature teaches young children a sense of beauty and develops their ability to evaluate their own behavior. These qualities are necessary for understanding the moral and ethical standards of conduct, cultivating the qualities of responsibility and commitment to others. In the process of communicating with nature, feelings of love and respect for friends, adults are formed. 
The following tasks are set for the methodology of teaching natural science:

to determine the role and place of nature science in the system of general education and complex education as a subject of study;

selection and synthesis of natural materials;

determination of its educational and upbringing tasks.

Formation of natural science concepts and their development by junior high school students The concepts of natural science are general knowledge about the whole group of objects, events, and bodies, which are combined with the most important features. For example, the term "plants" refers to a variety of things that are common to one group with important features common to all plants. They all grow; It evolves, breathes, reproduces, that is, living organisms. One must understand the concepts differently from the imagination. Imagination is the product of the sense organs, memory or imagination. Consciousness is a product of thinking. Concepts arise from reflection on what is accepted and imagined. For example, just look at a bird to visualize it. In order to form an understanding of that bird, we need to think about specific knowledge and systematize them. Perception and imagination are the images of some things. Concepts represent the generalized content of the whole class of things. For example, the word "leaf" applies to all the trees, shrubs, and grasses that grow on it. Imagery is a sensitive basis of concepts, but there is no sharp border between concepts and concepts. The ideas are summarized and understood as the content of the concepts becomes enriched and increasingly reflects the essential properties of things. At the same time, consciousness does not come into its own. The presence of ideas about certain things or objects of nature does not mean that they still exist. Consciousness is formed as a summarization of important features of certain events.

In the elementary school, children will gain a general understanding of the natural environment of plants and animals by familiarizing themselves with the environment, reading fairy tales and stories from the textbook. In the coming classes, they will gain specific insights into the nature of their experiments, observations, excursions, and practical activities.

In forming common concepts the teacher: organization of purposeful reception of objects;

analyzes each new understanding of natural objects and phenomena and distinguishes important features that are duplicated in all things, including earlier ones;

abstract all nonessential signs of secondary importance and use items that are of minor importance but retain important features (such as tulips and violets, owls and tulips).

In forming the concepts of natural science it is necessary to pay special attention to the use of various thought processes: analysis, synthesis, comparison, abstracting, specification, generalization. When creating an idea of a plant, animal or inanimate object (a compass, a thermometer), it is necessary to divide it into ideas and to look at each of them separately. For example, by introducing students in Grade 1 to early flowering plants (purple, chuchma, tulips), the teacher recommends that children divide these plants into parts (roots, stem, leaves and flowers), and then determine the function of each part. After that, children need to integrate parts of the thing into a whole, that is, use synthesis - Analysis and synthesis are the most important way of thinking, by which concepts are formed. By combining firewood, it is possible to compare certain things and events (violet and tulips; violet with violet, poppy, changes in plant life due to seasonal changes in nature)., seasons, usage, etc. Concepts are formed in the process of summarizing, that is, combining bodies and phenomena that have common features. Generalization is right when things and events are combined into important features.

The use of a variety of teaching methods, practical work, experience, and visual aids in the classroom will increase the understanding of new concepts. Conversations using thought-provoking questions, based on practical experience and experience, help strengthen them. Children should be able to apply the concepts to practice. For example, children need to learn about rivers, find them on a map, get an idea of plant reproduction, and see it in the corners of the wild or in the pre-school area. They should learn to monitor the weather, compare and draw conclusions (January, February - cold, March and April warmer).

When forming concepts, it is important to remember that the concept consists of some elements. Thus, the concept of "hill" consists of the following elements: depth, depth, steep slope, and slope slope. "The concept of a river includes the following elements: place of origin, head (beginning), creek, right 
and left bank. In order to get a clear idea of natural objects and phenomena, it is necessary to look at them first, then to look at their images (photos, tables, maps, schemes), listen to the story or conversation of the teacher, and strengthen the understanding of the textbook. The purposeful work of the teacher facilitates the successful formation of concepts.

Formation of Notions of Natural Science Single concepts are the individual features that are specific to certain things or events. If the common notion is reinforced by terms, the individual concept is represented by names or a personal name, since it does not contain any other object. It is important to draw readers' attention to the overall concept of the object, which is to emphasize the individual nature of the object. If it is a geographical object, it is necessary to give a spatial characteristic of the object, that is, its location on the map.

Methodological conditions that ensure the effective application of the concepts of natural science are not uncommon for students to master the material. This is because their knowledge is at the level of imagination. Concepts formed in this lesson or in one theme are not further developed and linked to other concepts. The necessary condition for the development of understanding is the system. In particular, the emergence of the concepts of natural science takes place under certain methodological conditions. Specifically, observations and perceptions of the natural object; the teacher's exciting story helps solve such issues. Teacher questions; Memory drawing, recognition activities, and recognition exercises help correct your imagination. Clear problem solving; the logic of reporting the teacher's teaching material; identification and comparison exercises; a repetition system that connects and develops concepts; questions that require generalization; questions that link concepts to skills will ensure that concepts are correct.

Natural perceptions can be straightforward in the context of perception - based on observations, a clear and clear picture of what is being studied or what is happening. Different types of objects and visual materials (tables, schemes, drawings, etc.) play a great role in the initial formation of the concept. It is not possible to achieve concepts without developing students' thinking and engaging them in thinking. In order to stimulate students' thinking activities, the teacher poses challenges for them at the beginning of the topic and at the beginning of the lesson. In describing the course material, it seeks to engage readers in identifying the causes and effects, the links between natural phenomena.

Interdisciplinary communication (speech development, reading, mathematics, mother tongue, music, singing, technical work, painting) plays an important role in understanding the concepts of natural science. Systematic use of interdisciplinary communication teaches children to apply previously acquired knowledge and to make logical connections in all types of educational activities. Teacher questions play a major role in fostering students' active thinking.

In natural science lessons, it is necessary to ask more questions that require generalization of synthesis and synthesis. In the answer, questions that require synthesis and expand understanding are of particular importance. The following questions may be an example: Which adaptations of desert animals can help them to survive drought and heat? Why can plants in hot climates grow on the Black Sea coast? What are the similarities of the steppe and desert nature? Why don't big trees grow in tundra? and so on.

A system of understanding questions includes comparing natural objects with their images on a table, drawing schemes, and mounting them on a blackboard. For example, there may be questions: What happens to the seeds after sowing? How to separate trees and bushes? Where and under what conditions does this plant grow? Is there a place to go south even when it is moving everywhere? (specify on map or globe). Give a schematic picture of the water cycle in nature. Students use a table to compare the external characteristics of plants and animals.

Experience is a practical method of teaching natural science. Experience is a method of teaching that creates conditions for determining the legitimacy of a studied phenomenon. During experiments, students form the ideas of natural science, which cannot be captured by other methods.

Experiments are a fun and effective way to get to know the world around us. They play an important role in the formation of material worldview, observation, logical thinking and speech development. It is a truly scientific way of knowing the properties of various natural bodies, which confirm the materiality of the world and its perception.

Experiences help children to translate abstract concepts into concrete concepts. For example, they are convinced that the mercury column of the thermometer will only rise and fall as the temperature 
changes during the experimental process. Only experience shows that water moves from one state to another. Typical experiments are performed by students independently at home, in the study area or in the corners of nature.

More sophisticated experiences are demonstrated by the teacher in the lesson. It is important to remember that the simplest experience is valuable not only by providing concrete knowledge, but also by understanding the process of observation and describing its results. Suppose students need to learn how to cool off the sun in relation to the Earth's surface in the classroom. The teacher conducts an experiment to explain this phenomenon. He grabs a thin sheet of paper on the burning candle. He holds one tape on top of the candle and the other on the candle. Students should tell which paper tape is lit earlier and explain why. Students should notice that this experience helps explain the sun's rays in the summer and fall. As the experiment progresses, students will come to the conclusion that in the fall, the sun will fall on the ground every day. Its incandescent light penetrates the surface and does not heat the air. That is why it is getting colder in the fall. In order to reinforce the material, it is necessary to draw or illustrate the experiences demonstrated by the teacher and the students themselves, and in some cases, both.

Experiments that require careful handling of tools and substances are conducted by the teacher himself. Before starting each experiment, the students should clearly explain its purpose, why the same instruments and substances were taken during the experiment, and write a plan to describe the experiment.

In the Living Corners or Learning Experimental Area, students will observe the growth of experimental and control plants in parallel, comparing their development, and recording the results of experimental work. Students draw a picture of the results of the experiment, write a summary in the notebook (mark the differences in the yield of the experiment and the observed plants). This practice is conducted prior to the study of the theme so that the students can absorb the material.

\section{CONCLUSION}

In conclusion, practical work plays an important role in the acquisition of knowledge about nature. Practical work teaches students to perform different types of labor operations during their activities. Practical activities include collecting natural materials during excursions, gardening in the pre-school and living areas, creating herbariums and collections, painting, modeling, and demonstration of weapons. Acquiring basic knowledge in the natural sciences teaches young people how to properly deal with nature. It is also a criterion for the conservation and rational use of natural resources to preserve the biodiversity of our native land.

\section{REFERENCES}

1. Gerasimova V. P. The animal world of our Motherland (A manual for teachers), M., "Enlightenment", 1977.

2. Gorshenko V.P., Stepanov I.A. Methodology of teaching natural history. M., "Enlightenment", 1984.

3. T h e r a n d. G., M a $1 \mathrm{k}$ i n a L. G. Introduce the environment. (A Handbook for Teachers.) T., "Teacher," 1986.

4. Dmitriev Yu. O. About nature for large and small. M., "Pedagogy", 1982.

5. Zapartovich B. B. et al. With love for nature. (Teaching material for elementary school). M., "Pedagogy", 1976.

6. Lyublinskaya A. A. Teacher on the psychology of a younger student. (A manual for the teacher). M., "Pedagogy", 1977.

7. Skatkin M. N. Methodology of teaching natural science in elementary school. M., Uchpedgiz, 1956.

8. Skatkin M. N. In non-class work on natural science in elementary school. M., Uchpedgiz. 1953.

9. S ukhlominsky V. A. Conversation with the young headmaster. M., "Pedagogy", 1973.

10. Skatkin M. H. Improving the learning process. M., "Pedagogy", 1971. 